\title{
Normalization of Blood Glucose in Diabetic Rats with Phlorizin Treatment Reverses Insulin-resistant Glucose Transport in Adipose Cells without Restoring Glucose Transporter Gene Expression
}

\author{
Barbara B. Kahn, ${ }^{*}$ Gerald I. Shulman, ${ }^{\dagger}$ Ralph A. Defronzo, Samuel W. Cushman," and Luciano Rossetti" \\ ${ }^{*}$ The Charles A. Dana Research Institute and Harvard-Thorndike Laboratory of Beth Israel Hospital, Department of Medicine, Beth \\ Israel Hospital and Harvard Medical School, Boston, Massachusetts 02215; ${ }^{\dagger}$ Department of Medicine, Yale University, New Haven, \\ Connecticut 06510; 'Diabetes Division, Department of Medicine, University of Texas Health Science Center, San Antonio, Texas 78284, \\ and "Experimental Diabetes, Metabolism and Nutrition Section, Molecular, Cellular and Nutritional Endocrinology Branch, National \\ Institute of Diabetes and Digestive and Kidney Disease, National Institutes of Health, Bethesda, Maryland 20892
}

\begin{abstract}
Evidence is emerging for a direct role of glucose, independent of changes in insulin, in the regulation of cellular glucose transport and glucose utilization in vivo. In this study we investigate potential cellular and molecular mechanisms for this regulatory effect of glucose by determining how normalization of glycemia without insulin therapy in diabetic rats influences 3-O-methylglucose transport and the expression and translocation of two genetically distinct species of glucose transporters (GTs) in adipose cells. These results are compared with alterations in glucose disposal in vivo measured by euglycemic clamp. In rats rendered diabetic by $90 \%$ pancreatectomy, insulin-stimulated glucose transport in adipose cells is decreased $50 \%$ in parallel with reduced insulin-mediated glucose disposal in vivo. Levels of adipose/muscle GTs measured by immunoblotting are decreased in adipose cell subcellular membrane fractions, as are the corresponding mRNA levels assessed by Northern blotting of total adipose cell RNA. Normalization of blood glucose in diabetic rats with phlorizin, which impairs renal tubular glucose reabsorption and thus enhances glucose excretion, restores insulin-stimulated glucose transport in adipose cells and insulin-mediated glucose disposal in vivo. Importantly, levels of the adipose/muscle GT protein remain $43 \%$ reduced in the lowdensity microsomes in the basal state and $46 \%$ reduced in the plasma membranes in the insulin-stimulated state. Adipose/ muscle GT mRNA levels remain $\sim 50 \%$ depressed. Levels of the HepG2/brain GT protein and mRNA are unaltered by diabetes or phlorizin treatment. Thus, changes in ambient glucose independent of changes in ambient insulin can regulate the glucose transport response to insulin in isolated adipose cells and changes in responsiveness parallel alterations in glucose uptake in vivo. Since this effect can occur without alteration in the expression of the two species of glucose transporters present in adipose cells or in their translocation to the plasma membrane in response to insulin, it may result from changes in GT functional activity. (J. Clin. Invest. 1991. 87:561-570.) Key words: euglycemia - hexose transport - glucose utilization - messenger RNA
\end{abstract}

Address reprint requests to Dr. Kahn, Diabetes Unit, Beth Israel Hospital, 330 Brookline Avenue, Boston, MA 02215.

Received for publication 12 July 1990 and in revised form 17 September 1990.

J. Clin. Invest.

(C) The American Society for Clinical Investigation, Inc

$0021-9738 / 91 / 02 / 0561 / 10 \$ 2.00$

Volume 87, February 1991, 561-570

\section{Introduction}

Insulin-resistant glucose uptake is a prominent feature of both type I, insulin-dependent diabetes mellitus (1-3), and type II, non-insulin-dependent diabetes mellitus (NIDDM) ${ }^{1}(4-6)$, in humans and of experimental models of diabetes in rats (7). This defect is evident in vivo as reduced glucose uptake in response to insulin measured by euglycemic clamp $(1-4,7)$ and in isolated adipose cells in vitro as reduced glucose transport response to insulin $(5,6,8)$. Both in vivo and in vitro defects are improved by insulin therapy $(2,3,5,9,10)$. Recent cloning studies have shown that adipose cells express at least two species of glucose transporters encoded by different genes: $(a)$ the adipose/muscle glucose transporter that is present predominantly in tissues in which glucose transport is highly responsive to insulin (11-15) and (b) the HepG2/brain glucose transporter which is widely expressed in both insulin-responsive and nonresponsive tissues (16-18). The adipose/muscle glucose transporter is the predominant species in adipose cells (19) and changes in levels of this transporter correspond qualitatively with changes in insulin-stimulated glucose transport in intact cells (20).

Recently protein and mRNA levels for the adipose/muscle glucose transporter have been shown to decrease with streptozotocin-induced diabetes in rats whereas expression of the HepG2/brain glucose transporter is unchanged (20-23). Chronic insulin therapy restores mRNA and protein levels for the adipose/muscle transporter $(20,21)$ while increasing insulin-stimulated glucose transport activity transiently to supranormal levels (9). The latter effect has been suggested to be due to increased glucose transporter intrinsic activity (moles of glucose transported per transporter per unit of time) $(9,10)$. In contrast, chronic insulin administration to normal rats has been shown to increase the adipose cell glucose transport response to insulin and glucose transporter number but not to alter transporter intrinsic activity (24).

Since the administration of insulin to diabetic or normal rats results in simultaneous and inverse alterations in plasma glucose and insulin concentrations, one cannot discern whether the changes in the glucose transport system result from increased insulinemia or decreased glycemia. Studies over the last few years have demonstrated that ambient glucose concentrations regulate glucose transport activity in several types of cells and tissues. Glucose starvation of cultured fibroblasts (25-

1. Abbreviation used in this paper: NIDDM, non-insulin-dependent diabetes mellitus. 
28), 3T3-L1 adipocytes $(29,30)$, muscle cells $(31,32)$, intact muscle (32), and glial cells (33) results in increased basal glucose transport which can reach maximal levels and thus obliterate any further stimulatory effect of insulin (32). In cultured glial (33) and muscle (31) cells, this effect of glucose starvation appears to result from increased expression of the HepG2/ brain glucose transporter. High glucose concentrations, on the other hand, studied in rat adipose cells in primary culture, decrease insulin-stimulated glucose transport but only when the exposure to glucose is in the presence of insulin (34). The mechanism appears to be impaired translocation of transporters from an intracellular pool.

Although ambient glycemia has been shown to affect glucose transport across the blood brain barrier $(35,36)$, less information is available on the in vivo role of changes in glycemia independent of changes in plasma insulin levels on glucose uptake and glucose transporter expression in classic insulin responsive tissues, i.e., skeletal muscle and adipose cells. Recently, Rossetti et al. (7) demonstrated that reversal of hyperglycemia in diabetic rats using phlorizin, an inhibitor of renal tubular glucose transport which results in enhanced renal glucose excretion, restores in vivo insulin-stimulated glucose disposal to normal. Sivitz et al. (37) showed that although shortterm phlorizin treatment (up to $23 \mathrm{~h}$ ) in diabetic rats restores euglycemia, adipose/muscle glucose transporter mRNA in adipose tissue remains suppressed at diabetic levels. Thus, the cellular and molecular mechanisms for the effect of phlorizin to restore in vivo insulin-responsive glucose uptake are not understood and are the subject of the current investigation. Using diabetic rats treated with phlorizin, we show that restoration of euglycemia in diabetic rats without insulin therapy corrects the impaired glucose transport response to insulin in adipose cells. This effect occurs without alteration in the expression of the two species of glucose transporters present in adipose cells or in their subcellular localization, and most likely results from changes in glucose transporter functional activity.

\section{Methods}

\section{Experimental design}

Male Sprague-Dawley rats (Charles River Breeding Laboratories, Inc., Wilmington, MA) were received at body weights ranging from 80 to 90 $\mathrm{g}$ and maintained with ad libitum feeding for $1 \mathrm{wk}$ before assignment to one of the following experimental groups: group I, sham-operated controls; group II, partially pancreatectomized rats; group III, partially pancreatectomized rats treated with phlorizin. $90 \%$ pancreatectomy was performed in groups II and III and sham pancreatectomy was performed in group I as previously described (7). In group III, phlorizin $(0.4 \mathrm{~g} / \mathrm{kg}$ body weight per day) was administered as a continuous subcutaneous infusion through a small implantable minipump (Alzet Osmotic Minipump, Alza Corp., Palo Alto, CA) to ensure constant inhibition of renal tubular glucose reabsorption. Phlorizin treatment was initiated 10-14 d after surgery when hyperglycemia first became evident in the partially pancreatectomized rats. After surgery, the rats received identical daily allotments of rat Chow (Ralston-Purina Co., St. Louis, MO) in an amount $(0.1 \mathrm{~g} / \mathrm{g}$ body weight per day) that sustained normal growth, based on previous experience, and which was completely consumed by all rats. Rats were weighed twice weekly at which time tail vein blood was collected for the determination of fed plasma glucose and insulin concentrations ( $1 \mathrm{~h}$ after eating). Fasting plasma glucose and insulin concentrations also were determined at least twice during the week before study. Full characterization of glucose and insulin profiles in response to meal tolerance tests and glucose tolerance tests has been previously published (7). $6 \mathrm{wk}$ after pancreatectomy or sham operation and 3-4 wk after the development of fasting hyperglycemia in the diabetic group, rats were studied as described below.

\section{Euglycemic clamp study}

Four animals from each group received a euglycemic insulin clamp study to document the presence of insulin resistance (7). 1 wk before the insulin clamp, indwelling catheters were inserted so that the animals could be studied in the awake, unstressed state (7). The insulin clamp was performed as previously described $(7,38)$. Briefly, $60 \mathrm{~min}$ before starting the insulin clamp, a prime $(6 \mu \mathrm{Ci} / \mathrm{min})$-continuous $(0.1$ $\mu \mathrm{Ci} / \mathrm{min}$ ) infusion of $\left[3-{ }^{3} \mathrm{H}\right] \mathrm{glucose}$ (New England Nuclear, Boston, MA) was initiated and continued throughout the study. Blood samples for the determination of plasma $\left[{ }^{3} \mathrm{H}\right]$ glucose specific activity were obtained at 5-min intervals from -30 to $0 \mathrm{~min}$ and 5-10 min intervals after starting the insulin infusion. At time zero a prime-continuous (12 $\mathrm{mU} / \mathrm{kg}$ per $\mathrm{min}$ ) infusion of regular insulin (Eli Lilly \& Co., Indianapolis, IN) was administered to acutely raise and maintain the plasma insulin concentration by $\sim 2.4 \mathrm{nM}(350 \mu \mathrm{U} / \mathrm{ml})$. In all groups a variable infusion of $25 \%$ glucose was started at time zero and periodically adjusted to clamp the plasma glucose concentration at $\sim 100 \mathrm{mg} / \mathrm{dl}$. Samples for plasma insulin concentration were obtained at 20-30-min intervals throughout the 90 -min insulin clamp study. To prevent intravascular volume depletion and anemia during the insulin clamp study, fresh whole blood obtained by heart puncture from littermates of the test animals, was infused at a constant rate designed to quantitatively replace the total amount of blood lost during the study. At the end of each insulin-clamp study, urine was collected and assayed for glucose.

Preparation of isolated adipose cells and measurement of cell size Rats were killed by brief exposure to $\mathrm{CO}_{2}$ followed by decapitation. Within 15-30 s, the whole epididymal fat pads were removed and isolated adipose cells were prepared as previously described $(9,20,24)$ Adipose cell size was determined by the osmic acid fixation, electronic counter method (Coulter Electronics, Inc., Hialeah, FL) as also previously described $(9,20,24)$.

Measurement of adipose cell glucose transport activity and intracellular water space. The isolated adipose cells were incubated at $37^{\circ} \mathrm{C}$ for $30 \mathrm{~min}$ in the presence of 0 or $7 \mathrm{nM}(1000 \mu \mathrm{U} / \mathrm{ml})$ insulin (crystalline porcine zinc, courtesy of Dr. Ronald B. Chance, Eli Lilly \& Co.). [3-O$\left.{ }^{14} \mathrm{C}\right]$ methyglucose transport was then assessed using a substrate concentration of $0.1 \mathrm{mM}$ by a modification described by Karnieli et al. (39) of the L-arabinose uptake method of Foley et al. (40). The intracellular water space was determined from the steady-state level of cellular 3-Omethylglucose. Initially glucose transport activity was measured in three separate experiments, each using pooled cells from two or three rats from groups I, II, and III. Rats were fasted overnight for $12-14 \mathrm{~h}$ so that they were treated identically to the rats that underwent the insulin clamp study. Subsequently, four additional glucose transport studies were performed on aliquots of cells from a minimum of 10 rats in each group which were prepared for subcellular fractionation. These rats were not fasted overnight. Adipose cell glucose transport results in the two groups were similar.

Preparation of adipose cell subcellular membrane fractions. Subcellular membrane fractions were prepared from a minimum of 10 control, pancreatectomized, or pancreatectomized/phlorizin-treated rats. Isolated adipose cells were incubated at $37^{\circ} \mathrm{C}$ for $30 \mathrm{~min}$ in the presence of 0 or $700 \mathrm{nM}$ insulin and samples were taken for determination of cell number and 3-O-methylglucose transport. (We have observed the same effects on glucose transport activity and transporter translocation with 7 and $700 \mathrm{nM}$ insulin. The maximally stimulating insulin concentration for both processes is $0.7 \mathrm{nM}$ [39].) Plasma, high-density microsomal, and low-density microsomal membrane fractions were prepared from the remaining cells by differential centrifugation using a combination of the usual large-scale preparation and the mini preparation, both as previously described (41). Membrane protein was determined by a modification (42) of the Coomassie Brilliant Blue method (protein assay, Bio-Rad Laboratories, Richmond, CA) (43) using crys- 
talline bovine serum albumin (Sigma Chemical Co., St. Louis, MO) as the standard.

\section{Immunoblotting}

Adipose cell subcellular membranes were subjected to $10 \%$ sodium dodecyl sulfate-polyacrylamide gel electrophoresis (SDS-PAGE) (44) and electrophoretically transferred to nitrocellulose filters. Identical membranes were used for detection of glucose transporters using two different antisera: a monoclonal antibody, 1F8, specific for the rat adipose cell/muscle glucose transporter (courtesy of Dr. David James, Washington University, St. Louis, MO) $(11,45)$; and a polyclonal rabbit antiserum prepared against a synthetic peptide consisting of the 16 $\mathrm{COOH}$-terminal amino acids of the HepG2 and rat brain glucose transporter sequence (courtesy of Dr. Bernard Thorens, Whitehead Institute, Cambridge, MA) (20). The antibody/antiserum was used at 10 $\mu \mathrm{g} / \mathrm{ml}$. Filters were blocked with $5 \%$ nonfat dry milk, washed, and incubated with ${ }^{125}$ I-protein A (New England Nuclear) after exposure to the HepG2 glucose transporter antiserum and ${ }^{125} \mathrm{I}-\mathrm{F}\left(\mathrm{ab}^{\prime}\right)_{2}$ fragment (Amersham Corp., Arlington Heights, IL) after exposure to 1F8. Dried filters were autoradiographed using XAR-5 film (Eastman Kodak Co. Rochester, NY) and intensifying screens at $-70^{\circ} \mathrm{C}$. The abundance of immunoreactive glucose transporters was quantitated using a scanning densitometer (GS 300, Hoefer Scientific Instruments, San Francisco, CA). The areas under the curves were calculated using the Hoefer GS 350 computer program. For comparison in some experiments glucose transporters were also quantitated by excising the bands and scintillation counting.

\section{RNA isolation}

A portion of the isolated adipose cells prepared as described above, were immediately frozen in liquid nitrogen, and stored at $-70^{\circ} \mathrm{C}$ for 1-14 d before RNA extraction using the guanadinium thiocyanate$\mathrm{CsCl}$ technique (46).

\section{Northern blotting}

RNA was electrophoresed on $1.2 \%$ formaldehyde agarose gels (47), blotted, and fixed onto nylon filters, and then hybridized with cRNA or cDNA probes for the glucose transporters and a cDNA probe for actin.

The rat muscle glucose transporter cDNA probe (courtesy of Dr. David Moller, Beth Israel Hospital) (48), the HepG2 glucose transporter cRNA probe (courtesy of Dr. Mike Mueckler, Washington University) (16) and the $\beta$-actin cDNA probe (courtesy of Dr. B. Rollins,
Dana Farber Cancer Institute) (49) were labeled and hybridizations were carried out under high stringency as previously described (20). Dried filters were autoradiographed and densitometry was performed as for immunoblots.

\section{Analytical procedures}

Plasma glucose concentration was measured by the glucose oxidase methods (glucose analyzer, Beckman Instruments, Inc., Palo Alto, CA). Plasma insulin concentration was determined by radioimmunoassay using rat insulin (lot 615-D63-12-3, Eli Lilly \& Co.) standards (50). Plasma $\left[3-{ }^{3} \mathrm{H}\right]$ glucose radioactivity was measured in duplicate in the supernatant of barium hydroxide zinc sulphate precipitates of plasma samples after evaporation to dryness to eliminate $\left[{ }^{3} \mathrm{H}\right] \mathrm{H}_{2} \mathrm{O}$.

\section{Calculations and statistical analyses}

Data for total body glucose uptake and hepatic glucose production represent the means of five values during the last $30 \mathrm{~min}$ of the basal period and the insulin clamp study. During the last $30 \mathrm{~min}$ of the basal period and during the last $30 \mathrm{~min}$ of the insulin clamp study, a steadystate plateau of $\left[{ }^{3} \mathrm{H}\right]$ glucose radioactivity was achieved in all studies. Total body glucose turnover was calculated by dividing the infusion rate of $\left[{ }^{3} \mathrm{H}\right]$ glucose (counts per minute) by the steady-state plateau of $\left[{ }^{3} \mathrm{H}\right]$ glucose specific activity (counts per milligram). The rate of hepatic glucose production was calculated by subtracting the exogenous glucose infusion rate from the rate of total body glucose turnover. Negative numbers for hepatic glucose production were not observed.

Calculations of 3-O-methyglucose transport and adipose cell size were carried out on the Dartmouth Time Sharing System computer facilities. Statistical analyses were performed on the Beth Israel Hospital Analyzer System using analysis of variance and the Newman-Keuls test. For densitometry data a one sample comparison test was used since these results are evaluated as a percentage of control due to the arbitrary nature of optical density units. Differences were accepted as significant at the $P \leq 0.05$ level.

\section{Results}

Body weight, plasma glucose, and insulin concentrations and adipose cell characteristics. At the time of study, $6 \mathrm{wk}$ after pancreatectomy the body weights are similar in control, diabetic, and diabetic/phlorizin-treated rats (Table I). The fasting

Table I. General Characteristics of the Experimental Groups: Body Weight, Plasma Glucose, Insulin, and Adipose Cells Characteristics in Controls (Group I), Diabetics (Group II), and Diabetics Treated with Phlorizin (Group III)

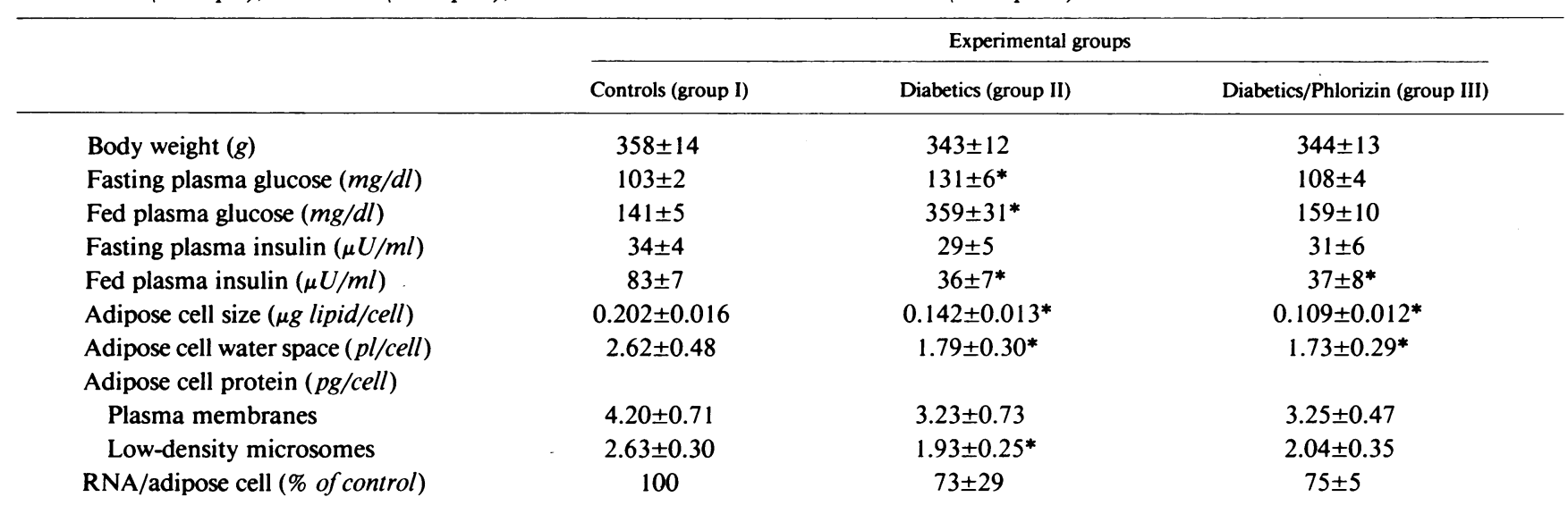

Rats were made diabetic and treated with phlorizin as described in Methods. Body weight and plasma glucose and insulin concentrations were determined twice weekly on 17-20 rats in each experimental group also as described in Methods. Adipose cell size, intracellular water space, protein, and RNA were determined on pooled cells from 2-10 rats in each group in each of seven, seven, four, and three separate experiments, respectively. Results are means \pm SEM. ${ }^{*}$ Difference from control at $P \leq 0.05$. 


\begin{tabular}{|c|c|c|c|c|c|c|c|}
\hline \multirow[b]{2}{*}{ Group } & \multirow[b]{2}{*}{$n$} & \multirow{2}{*}{$\begin{array}{l}\text { Insulin } \\
\text { infusion } \\
\text { rate }\end{array}$} & \multirow{2}{*}{$\begin{array}{l}\text { Steady-state } \\
\text { plasma } \\
\text { insulin }\end{array}$} & \multirow{2}{*}{$\begin{array}{l}\text { Steady-state } \\
\text { plasma } \\
\text { glucose }\end{array}$} & \multicolumn{2}{|c|}{ Hepatic glucose production } & \multirow{2}{*}{$\begin{array}{c}\text { Glucose } \\
\text { rate of } \\
\text { disappearance }\end{array}$} \\
\hline & & & & & Basal & Insulin & \\
\hline & & $\mathrm{mU} / \mathrm{kg} \cdot \min$ & $\mu U / m l$ & $m g / d l$ & \multicolumn{2}{|c|}{$\mathrm{mg} / \mathrm{kg} \cdot \min$} & $\mathrm{mg} / \mathrm{kg} \cdot \min$ \\
\hline 1. Controls & 4 & 12 & $425 \pm 23$ & $103 \pm 1$ & $7.1 \pm 0.2$ & $0.5 \pm 0.3$ & $33.6 \pm 0.7$ \\
\hline II. Diabetics & 4 & 12 & $422 \pm 23$ & $107 \pm 2$ & $7.6 \pm 0.3$ & $0.8 \pm 0.4$ & $24.6 \pm 0.7^{*}$ \\
\hline III. Diabetics/Phlorizin & 4 & 12 & $410 \pm 28$ & $103 \pm 2$ & $7.4 \pm 0.2$ & $0.5 \pm 0.2$ & $33.4 \pm 1.0$ \\
\hline
\end{tabular}

* Difference from control at $P \leq 0.05$.

and postmeal plasma glucose concentrations are significantly increased in the diabetic compared to the control group and return to normal after phlorizin treatment (Table I) similar to our previously published results with this model (7). The fasting plasma insulin concentrations are similar in the three groups whereas the postmeal plasma insulin response is reduced by $>50 \%$ in diabetic compared to control rats. Phlorizin treatment of diabetic rats does not alter the plasma insulin concentrations, while normalizing the plasma glucose concentrations (Table I).

In partially pancreatectomized diabetic rats, adipose cell size and intracellular water, a reflection of intracellular protein, are reduced $\sim 30 \%$ (Table I). Phlorizin treatment further decreases cell size to $54 \%$ of control and maintains intracellular water space at $66 \%$ of control. Adipose cell plasma membrane and low-density microsomal membrane protein tend to decrease $\sim 25 \%$ in diabetic rats with or without phlorizin treatment. Only the differences in low-density microsomes from diabetic rats reach statistical significance. Total RNA per adipose cell is not significantly altered in diabetic rats with or without phlorizin treatment.

Euglycemic insulin clamp studies. To compare changes in cellular glucose transport and glucose transporter expression in isolated adipose cells with in vivo glucose uptake, we repeated euglycemic clamp studies. Glucosuria was not detected in any of the groups at the end of the insulin clamp study. Consistent with our previous reports (7), Table II shows that $90 \%$ pancreatectomy in rats leads to in vivo insulin-resistant glucose utilization. The correction of chronic hyperglycemia with phlorizin normalizes the insulin-mediated glucose disposal. The steadystate plasma insulin and glucose concentrations during the insulin clamp studies are similar in all three experimental groups. Basal hepatic glucose production is similar in all three groups and is suppressed by $>90 \%$ during the insulin infusion. Insulin-mediated total body glucose uptake is significantly reduced by $27 \%$ in the diabetic compared to the control group and phlorizin treatment in the diabetic rats restores insulin-mediated glucose disposal to normal (Table II).

Glucose transport activity in adipose cells. Fig. 1 illustrates the effects of diabetes and subsequent normalization of blood glucose with phlorizin treatment on 3-O-methylglucose transport in isolated adipose cells. Basal glucose transport activity per cell is not significantly altered with diabetes or phlorizin treatment (Fig. $1 \mathrm{~A}$ ). In contrast, maximally insulin-stimulated transport activity per adipose cell decreases $50 \%$ from control levels with diabetes and is restored to control levels with phlorizin treatment. When expressed per cellular surface area (Fig. 1 $B$ ) because of the smaller size of the cells from diabetic rats and further decrease after phlorizin treatment, basal glucose transport is slightly increased (29\%) with pancreatectomy alone and is increased $104 \%$ with phlorizin treatment compared to control. Maximally insulin-stimulated glucose transport per cellular surface area decreases $30 \%$ with diabetes and is increased to $134 \%$ of control and $\sim 190 \%$ of diabetic levels with phlorizin treatment.

Immunoreactive glucose transporters in adipose cells. Adipose/muscle and HepG2/brain glucose transporters were assessed in adipose cell subcellular membrane fractions by immunoblotting with anti-glucose transporter antibody/antiserum specific for each of these transporters. Both probes recognize a protein of $M_{\mathrm{r}} \sim 43-50 \mathrm{kD}$ (Fig. 2), which is sometimes present as a doublet, as previously described $(45,51)$. With the antiHepG2 glucose transporter antiserum a fainter, higher molecular mass band is also seen (Fig. $2 \mathrm{~B}$ ), which has previously been reported to be nonspecific (52).

Fig. $2 A$ shows two exposures of immunoblotting with antibody $1 \mathrm{~F} 8$. The darker exposure (top panel) shows that in adipose cells from diabetic and phlorizin-treated rats, there is a very slight increase in levels of the adipose/muscle glucose transporter in plasma membranes in the basal state. In contrast, in plasma membranes from cells in the insulin-stimulated state the relative number of transporters is decreased $46 \%$
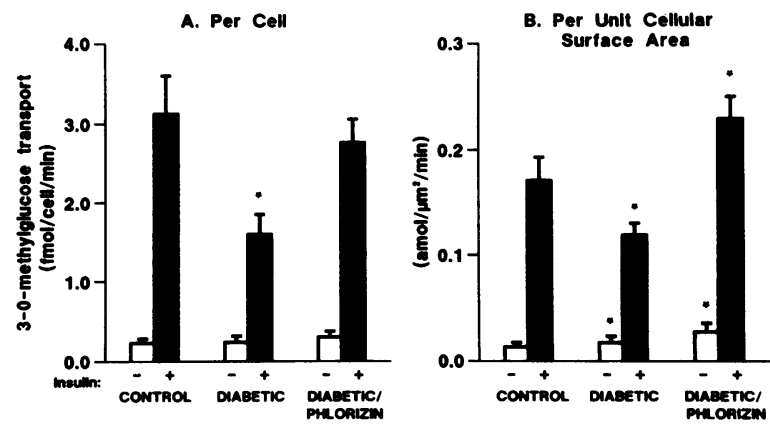

Figure 1. Glucose transport activities expressed $(A)$ per cell or $(B)$ per cellular surface area in basal and maximally insulin-stimulated adipose cells from control, diabetic, and phlorizin-treated diabetic rats. Diabetes was induced by $90 \%$ pancreatectomy; some of the diabetic rats were infused with phlorizin subcutaneously as described in Methods. Isolated adipose cells were prepared from the epididymal fat pads of 2-10 rats in each group, incubated for $30 \mathrm{~min}$ at $37^{\circ} \mathrm{C}$ in the absence or presence of $7 \mathrm{nM}$ insulin and sampled for measurement of 3-O-methylglucose transport. Results are means \pm SEM of the mean values from at least quadruplicate samples in each of seven separate experiments. ${ }^{*}$ Difference from control at $P \leq 0.05$. 


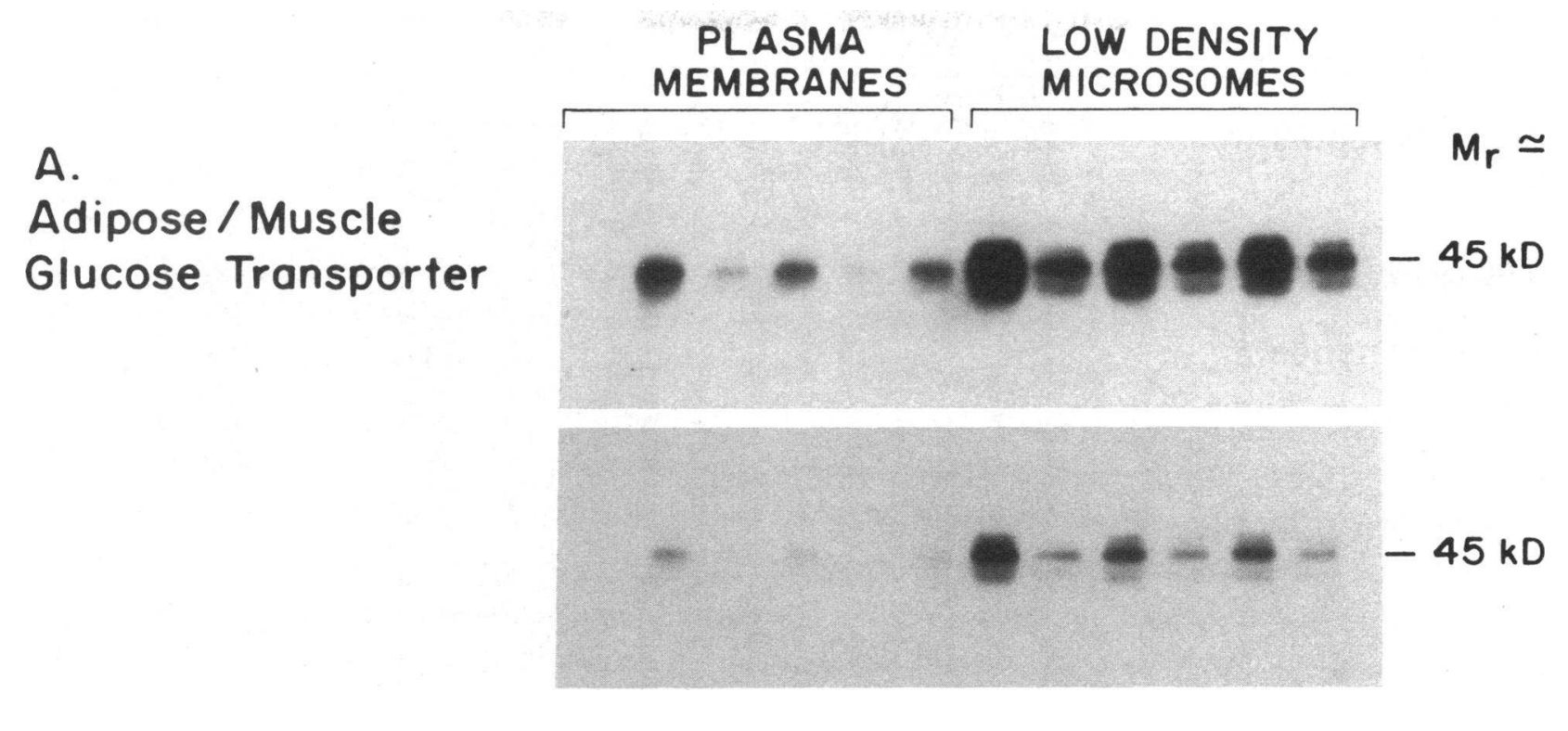

B.

\section{HepG2 / Brain Glucose Transporter}
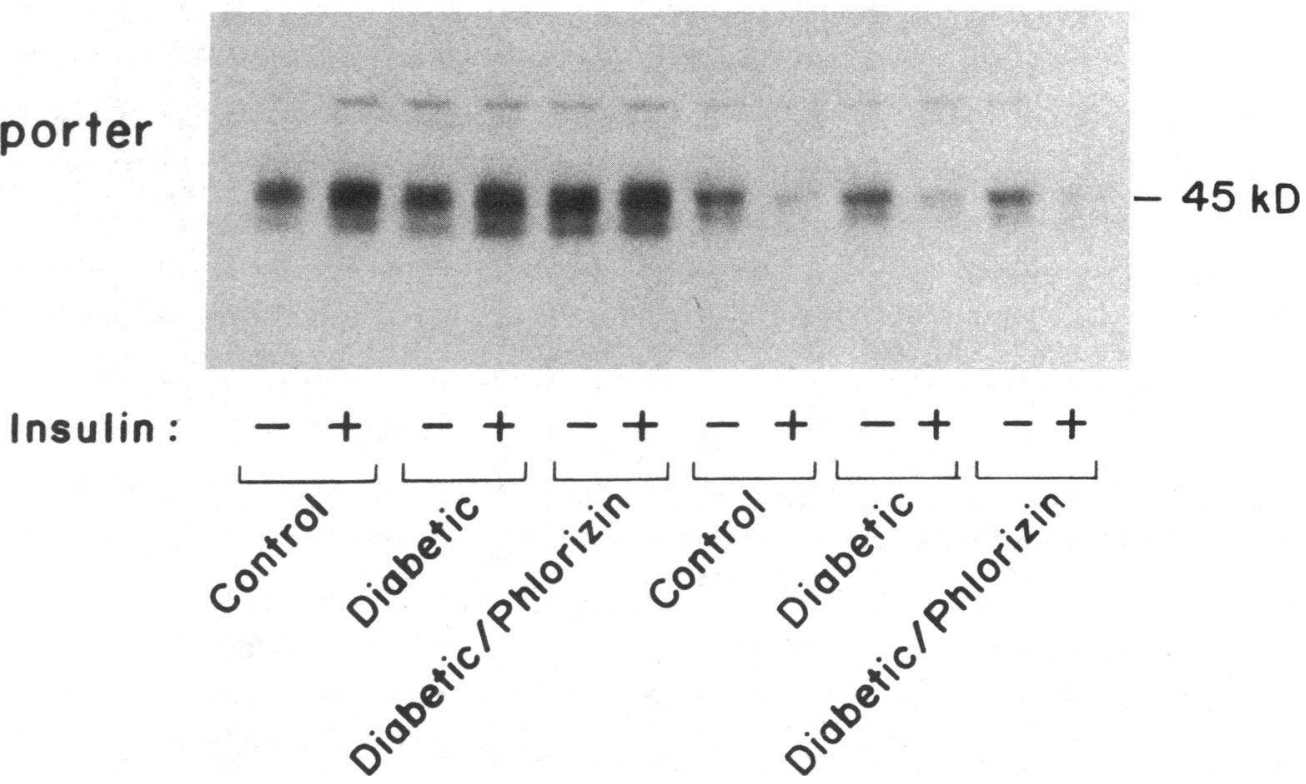

Figure 2. Immunological detection of glucose transporters in subcellular membrane fractions of basal and maximally insulin-stimulated adipose cells from control, diabetic, and phlorizin-treated diabetic rats. Isolated cells were prepared and incubated with or without $700 \mathrm{nM}$ insulin as described in Methods. Subcellular membrane fractions were prepared and glucose transporters were assessed by immunoblotting using $(A)$ antirat adipose/muscle glucose transporter antibody, $1 \mathrm{~F} 8(11,45)$ and $(B)$ anti-carboxyl terminus HepG2 glucose transporter antiserum $(20)$. Panel $A$ contains two different exposures of the same blot. Each lane was loaded with $35 \mu \mathrm{g}$ of protein. These blots are representative of four separate experiments.

with diabetes and remains similarly depressed with phlorizin treatment.

In low-density microsomes from adipose cells in the basal state adipose/muscle glucose transporters are reduced $46 \%$ with diabetes and $43 \%$ with phlorizin treatment. These changes are more evident in the lighter exposure (lower panel). In all groups of rats, $60-75 \%$ of adipose/muscle glucose transporters disappear from the low-density microsomes in response to insulin. However, the reduced number in this fraction in the basal state in cells from diabetic rats before and after phlorizin treatment is associated with fewer transporters recruited to the plasma membrane of these cells in response to insulin.

In contrast, immunoblotting of the identical adipose cell membranes with an antiserum to the HepG2 glucose transporter (Fig. $2 B$ ) shows no significant alteration in the relative amount of this transporter in plasma membranes in the insulin-stimulated state or low-density microsomes in the basal state from diabetic rats before or after phlorizin treatment. There is a slight increase in the relative abundance of glucose transporters in the plasma membranes in the basal state with 


\section{Adipose/Muscle}

glucose transporter

HepG2/Brain

glucose transporter

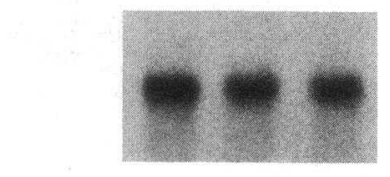

Actin

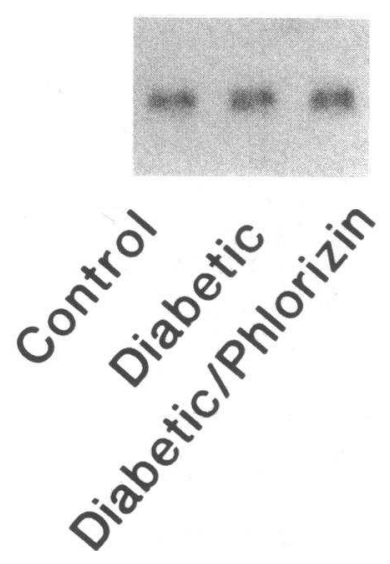

diabetes and with phlorizin treatment. In cells from all three states, insulin results in a 1.3-1.8-fold increase in HepG2/brain transporters in the plasma membranes and a 3.6-4.7-fold decrease from the low-density microsomes.

Specific marker enzymes measured in a subset of experiments revealed no differences in the recoveries or cross-contamination of membrane fractions from the three groups of rats (data not shown). Therefore relative numbers of glucose transporters in the subcellular fractions in the different states can be directly compared.

$m R N A$ levels for specific glucose transporters and actin in adipose cells. Both the HepG2/brain and adipose/muscle glucose transporter antisense RNAs or cDNAs hybridize under stringent conditions with a single $2.7-2.8$-kb transcript in adipose cells shown in Fig. 3 (left). The size of this transcript is unaltered by diabetes resulting from partial pancreatectomy or by subsequent phlorizin treatment. Densitometric scanning of several blots (Fig. 3, right) reveals that the abundance of the adipose/muscle transporter mRNA is decreased $\sim 50 \%$ with diabetes and remains depressed with phlorizin treatment. Levels of the HepG2/brain transporter mRNA are not significantly altered by diabetes or phlorizin treatment. Because there is no change in total RNA per adipose cell (Table I), the relative mRNA levels per microgram of RNA reflect the relative levels per adipose cell and can be directly compared to glucose transport and transporter number per cell. Actin mRNA abundance is unchanged with diabetes before or after phlorizin treatment (Fig. 3, both panels).

Comparison of the acute effects of insulin on glucose transporter levels in plasma membranes, glucose transport in intact cells, and in vivo glucose disposal. Fig. 4 compares insulinstimulated 3-O-methylglucose transport in intact cells with the

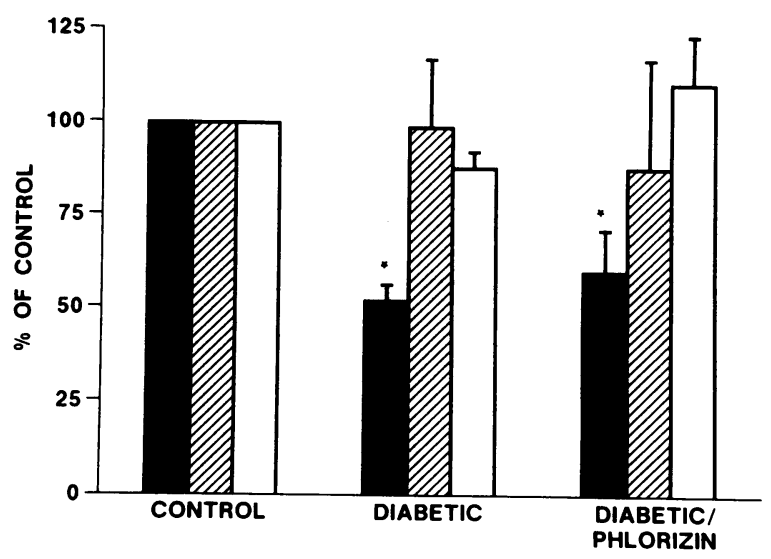

Figure 3. Detection of adipose/muscle glucose transporter (ø), HepG2/brain glucose transporter (回), and actin (ㅁ) mRNA in adipose cells from control, diabetic, and phlorizin-treated diabetic rats by Northern gel blot analysis. Isolated cells were prepared and sampled as described in Fig. 1, RNA was extracted, and Northern analysis (left) was performed as described in Methods. $20 \mu \mathrm{g}$ of RNA were loaded on each lane. Blots were hybridized with cRNA or CDNA probes as described in Methods. Autoradiograms were exposed for 4-10 d for glucose transporters and $6 \mathrm{~h}$ for actin at $-70^{\circ} \mathrm{C}$. These blots are representative of three Northern blots performed on three separate experiments. (Right) Quantitative densitometry as means \pm SEM of the three blots. *Difference from control at $P \leq 0.05$.

numbers of glucose transporters in the corresponding plasma membranes and with glucose uptake in vivo. To make the most direct comparison, the transport data shown here are from aliquots of the exact cell suspensions from which subcellular

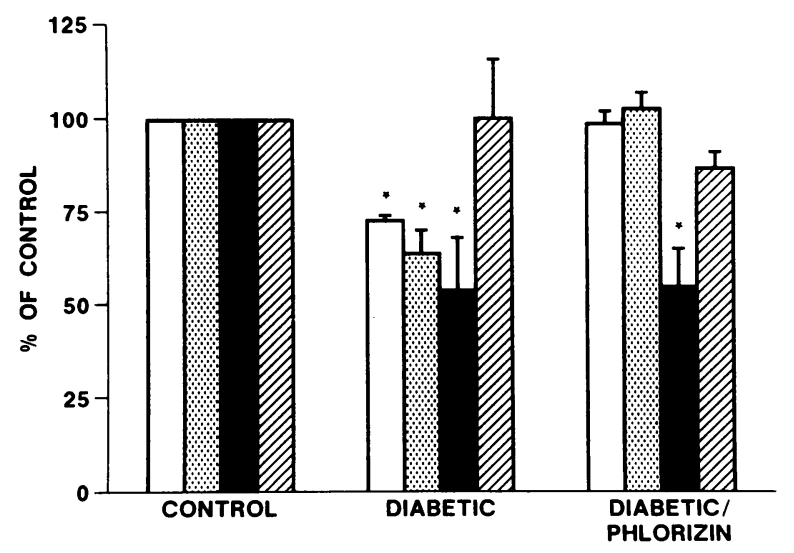

Figure 4. Comparison of insulin-stimulated glucose disposal in vivo (), insulin-stimulated glucose transport in intact adipose cells ( $\square$ ), and immunoreactive adipose/muscle ( $\square$ ) and HepG2/brain ( $\square$ ) glucose transporters in plasma membranes from insulin-stimulated cells. Insulin-stimulated 3-O-methylglucose transport results are for the specific experiments $(n=4)$ in which subcellular membranes were made. Plasma membrane glucose transporter values represent quantitative densitometry of four immunoblots performed as described in Fig. 2. Results are the mean \pm SEM of four separate experiments. For each experiment results in diabetic and phlorizintreated diabetic rats are expressed as a percentage of the corresponding control. 
membranes were made ( $n=4$ rather than $n=7$ in Fig. 1 ). In diabetic rats, insulin-resistant glucose uptake in vivo is parallelled by a reduced glucose transport response to insulin in adipose cells and reduced levels of immunoreactive adipose/ muscle glucose transporters in the corresponding plasma membranes (Fig. 4). Phlorizin treatment restores glucose uptake both in vivo and in adipose cells in vitro but does not restore the levels of the adipose/muscle glucose transporter. The relative levels of the HepG2/brain transporter in plasma membranes from insulin-stimulated cells are unaltered by diabetes or phlorizin treatment.

\section{Discussion}

Using phlorizin to achieve euglycemia in diabetic rats, we demonstrate that changes in glycemia independent of changes in insulinemia regulate the glucose transport response to insulin in adipose cells without significantly altering the expression of two distinct species of glucose transporters in these cells. $90 \%$ pancreatectomy in rats leads to a relatively mild form of diabetes which is associated with only slightly elevated fasting blood glucose and more significantly elevated postprandial glucose concentrations. However, similar to the more severe streptozotocin-induced diabetes studied previously $(8,20,21)$, this nonpharmacological form of diabetes results in decreased glucose transport in isolated adipose cells (Fig. 1) and decreased levels of the adipose/muscle but not the HepG2/brain glucose transporter (Fig. 2). As with streptozotocin diabetes, diabetes resulting from partial pancreatectomy has a pretranslational effect on the expression of the adipose/muscle glucose transporter as evidenced by decreased mRNA levels for this transporter (Fig. 3).

On the other hand, normalization of glycemia with phlorizin restores glucose transport activity (and in vivo glucose uptake) without restoring adipose/muscle glucose transporter mRNA or protein levels (Figs. 1-4). This is in marked contrast to the effects of normalization of blood glucose in streptozotocin diabetic rats with insulin which increases adipose/muscle glucose transporter protein and mRNA to 8.5- and 13-fold diabetic levels, respectively (20). Thus, more than one mechanism exists by which treatment of hyperglycemia can reverse the impaired glucose transport response to insulin in adipose cells and the therapeutic modality in vivo determines the molecular mechanism which prevails.

Fig. 5 extends a schema which we previously developed (9) to show that altered metabolic states can affect both glucose transporter number and intrinsic activity. Here glucose transporters measured by cytochalasin $B$ binding $(8,39)$ and/or by immunoblotting with an antibody to the adipose/muscle glucose transporter are compared to insulin-stimulated glucose transport in intact cells. Transporters measured by either of these methods can be used nearly interchangeably in the comparison since the majority of D-glucose-inhibitable cytochalasin B binding in the rat adipose cell is to the adipose/muscle transporter species and very little binds to the HepG2/brain transporter $(19,53)$. Furthermore, we have previously shown a close correlation in adipose cells from diabetic and insulintreated diabetic rats between the relative number of transporters measured by cytochalasin B binding and by immunoblotting with this antibody (20).

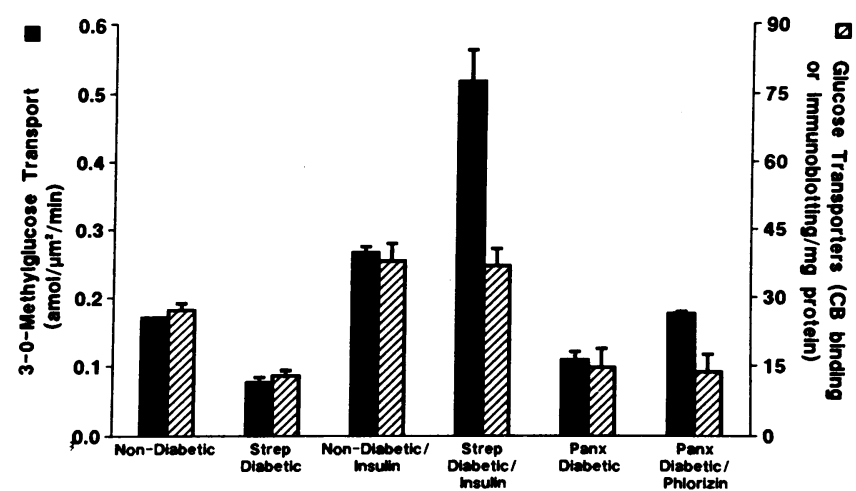

Figure 5. Comparison of insulin-stimulated glucose transport activity in intact adipose cells and glucose transporters in plasma membranes from the same cells in rat models of hypo- and hyperinsulinemia and hypo- and hyperglycemia. Isolated adipose cells were prepared, 3-Omethylglucose transport was measured as described for Fig. 1, and glucose transporters in plasma membranes were assessed either by cytochalasin B binding ( $C B$ binding) as previously described $(9,39)$ or by immunoblotting with an anti-adipose/muscle glucose transporter antibody (20), as described in Methods. CB binding results are $\mathrm{pmol} / \mathrm{mg}$ membrane protein. Immunoblotting results are OD units per milligram of membrane protein expressed relative to the corresponding control value. The results in streptozotocin (Strep) diabetic rats are taken from Karnieli et al. (8), nondiabetic/insulininfused rats from Kahn et al. (24), and streptozotocin diabetic/insulin infused rats from Kahn et al. $(9,20)$. Panx $=90 \%$ pancreatectomized.

Under normal conditions insulin-stimulated glucose transport in intact adipose cells is proportional to the number of glucose transporters in the corresponding plasma membranes (Fig. 5). With diabetes induced by streptozotocin $(8,20,21)$ or by partial pancreatectomy both of these parameters are proportionally decreased. With hyperinsulinemia resulting from insulin infusion in nondiabetic rats (24) or naturally occurring in genetically obese Zucker rats (54) (data not shown), transport activity and transporters are proportionally increased. But with insulin treatment of diabetic rats, glucose transport is increased out of proportion to the slightly increased number of glucose transporters in plasma membranes from insulin-stimulated cells. Because this increased transport rate is due to an increase in the maximal velocity of glucose transport $\left(V_{\max }\right)$ and it cannot be explained by an increase in glucose transporter number, it appears to result from an increase in transporter intrinsic activity $(9,10)$. Now we show that normalization of blood glucose with phlorizin restores insulin-stimulated glucose transport without increasing the relative number of transporters in the corresponding plasma membranes and thus, most likely affects glucose transporter intrinsic activity alone. In fact, the effect of insulin treatment of diabetic rats may reflect a combination of the effect of normalization of blood glucose to enhance glucose transporter intrinsic activity and the effect of insulin to increase glucose transporter number.

Although an effect of phlorizin treatment on the $K_{\mathrm{m}}$ of the transporter for glucose cannot be ruled out by our data, the regulatory effect of glucose on glucose transport in cultured myocytes and myotubes $(32)$ and in $3 T 3-\mathrm{L} 1$ adipocytes $(29,30)$ is entirely a $V_{\max }$ effect without measurable changes in $K_{\mathrm{m}}$. Furthermore, we have previously shown in diabetic rats that 
the effect of insulin therapy to increase glucose transport in adipose cells is entirely a $V_{\max }$ effect (9).

The effect of hyperinsulinemia to increase glucose transporter number is associated with a generalized anabolic effect of insulin to increase net protein synthesis $(9,10,20,24)$. In contrast, in this study restoration of euglycemia by enhancing glucose excretion with phlorizin does not have this anabolic effect. In diabetic rats treated with phlorizin, this is evident by the decreased adipose cell size and intracellular water space, similar to or even more depressed than levels in untreated diabetic rats (Table I). Insulin therapy of diabetic rats, on the other hand, increases cell size toward control levels and increases intracellular water space to $\sim 60 \%$ greater than control $(9,20)$. Additionally, insulin therapy results in a 2.4 -fold increase in total RNA per adipose cell and raises mRNA levels for both the adipose/muscle and HepG2/brain glucose transporters. In contrast, phlorizin treatment has no effect on total adipose cell RNA (Table I) or mRNA levels for either transporter (Fig. 3).

We considered whether phlorizin per se, rather than normalization of blood glucose, may directly affect glucose transport. This is unlikely since in initial studies we treated normal, nondiabetic rats with phlorizin and found no effect on plasma glucose levels or insulin-mediated glucose uptake (7).

Basal glucose transport expressed per cellular surface area and the number of adipose/muscle glucose transporters in plasma membranes of adipose cells in the basal state (absence of insulin) are increased in diabetic rats treated with phlorizin. The physiological significance of these changes is unknown. Since fasting insulin concentrations (Table I) are normal $(29 \pm 5$ $\mathrm{uU} / \mathrm{ml}$ ) in partially pancreatectomized rats, a true absence of insulin at the tissue level is unlikely. Furthermore, basal transport rates are extremely low compared to insulin-stimulated rates (Fig. 1).

The potential contribution of increased basal transport activity to the insulin-stimulated activity can be taken into account by subtracting the basal activity from the insulin-stimulated activity in each experimental group. The resulting "net" insulin-stimulated glucose transport activities are: control $1.58 \pm 0.22$, diabetic $1.02 \pm 0.13$, diabetic/phlorizin-treated $2.01 \pm 0.23 \mathrm{fmol} / \mu \mathrm{m}^{2}$ per min (mean $\pm \mathrm{SEM}$ ). Hence, even after taking into account the differences in basal transport activity among the experimental groups, the insulin-stimulated glucose transport activity is decreased $35 \%$ in the diabetic rats and not only restored but increased to $127 \%$ of control and nearly $200 \%$ of diabetic levels in phlorizin-treated rats. Most importantly, normalization of blood glucose with phlorizin treatment doubles net insulin-stimulated glucose transport but does alter the number of glucose transporters in the corresponding plasma membranes.

Although the adipose/muscle transporter is the major species in adipose cells (19), markedly increased expression of another glucose transporter could be responsible for the restored glucose transport response to insulin. This is unlikely to be attributable to the HepG2/brain glucose transporter since levels of that transporter protein and mRNA also are unaffected by phlorizin treatment (Figs. 2-4). However, another as yet unidentified transporter could be mediating the activity. The expression of the adipose/muscle glucose transporter is decreased in adipose cells of both streptozotocin diabetic and fasted rats, two hypoinsulinemic conditions in which blood glucose changes in opposite directions. These observations led to the hypothesis that ambient insulin levels were critical in the regulation of glucose transporter gene expression and thus glucose transport activity $(22,23,37)$. Indeed, chronic insulin exposure has been shown to increase mRNA and protein levels for the HepG2/brain glucose transporter in L6 muscle cells (31), 3T3L1 adipocytes (55) and human fibroblasts (56). However, levels of the adipose/muscle transporter in 3T3L1 adipocytes in which both transporters are expressed failed to be affected by insulin (55).

In the current study we show that normalization of blood glucose even in the face of hypoinsulinemia can restore the glucose transport response to insulin, suggesting that changes in plasma glucose levels independently regulate insulin-responsive glucose transport. Theoretically, the effects of phlorizin treatment on glucose transport and transporters in adipose cells of diabetic rats could be mediated by metabolic changes other than normalization of blood glucose. However, we have found no effect of phlorizin in diabetic rats on various metabolic parameters including plasma levels of insulin (Table I), glucagon $(57,58)$, free fatty acids $(57,58)$, or catecholamines (unpublished observations). In support of the regulatory effects of changes in glucose levels in vivo are the observations that in rat adipose cells in culture physiological glucose concentrations in the presence of insulin result in decreased insulin-stimulated glucose transport in a dose-dependent manner (59). The interpretation of this observation was that the intracellular metabolism of glucose is a primary regulator of insulin-responsive glucose transport and that glucose or a metabolite negatively feeds back to decrease insulin responsiveness and sensitivity. The effect of insulin then is simply to enhance the uptake of glucose into the cell.

However, unlike these cells in culture in which impaired translocation of glucose transporters appears to be the mechanism for the insulin resistant glucose transport induced by glucose (34), the translocation mechanism remains intact in our in vivo model of hyperglycemia. Taking these results together with the findings in streptozotocin diabetic and fasted rats (2023), it appears that hypoinsulinemia may decrease insulin-responsive glucose transport at least in part by decreasing expression of the adipose/muscle glucose transporter gene, whereas hyperglycemia may primarily affect the functional activity of the transporters. Our current results are relevant to the pathophysiology of insulin resistance in humans with NIDDM in which insulin levels are increased or normal with increased ambient glucose concentrations.

The changes we observe here in glucose uptake in isolated adipose cells are reflected by in vivo glucose uptake as measured by euglycemic clamp (Fig. 4). Studies comparing in vivo insulin-mediated glucose disposal and maximally insulin-stimulated glucose transport in isolated adipose cells from human type II diabetics have shown correlations ranging from 0.36 (60) to 0.71 (4). One study noted a correlation of 0.88 between the percent improvement in adipose cell glucose transport and the in vivo glucose disposal rate after insulin therapy (5). The major tissue determining glucose uptake measured by euglycemic clamp is muscle, not adipose cells (61). The extent and time frame of the effect of glucose to induce insulin resistant glucose uptake in isolated soleus muscle (32), cultured myocytes and myotubes (32) and in perfused hindlimb (62) closely 
parallels the process in adipose cells, suggesting a possible common mechanism (59) in the two tissues. This could explain the correlation between glucose uptake in vivo and glucose transport in isolated adipose cells in our study. However, alterations in glucose transporter expression and activity need to be studied in skeletal muscle under the same metabolic conditions used in this study.

In summary, changes in ambient glucose levels independent of changes in insulin levels can profoundly alter the glucose transport response to insulin in adipose cells. Whereas the effect of insulinemia on glucose transport appears to be at least partly due to pretranslation regulation of the expression of the major glucose transporter in adipose cells $(20,21,23)$, the effect of glucose occurs without alteration in glucose transporter gene expression or in the subcellular distribution of transporters. Therefore, changes in ambient glucose levels appear to alter the functional activity of glucose transporters. Effects at the cellular level correspond to changes in vivo suggesting that this may be an important mechanism for regulating insulin responsiveness in vivo especially in insulin resistant states such as NIDDM.

\section{Acknowledgments}

We are indebted to Dr. J. S. Flier for his encouragement in the course of this work and for critically reading the manuscript. We thank Drs. D. James, B. Thorens, D. Moller, and M. Mueckler for providing critical antibodies/antisera and cDNA probes; Dr. M. Charron for probing an initial Northern blot; A. Rosen, M. J. Zarnowski, D. Yver, E. KleinRobbenhaar, and L. Bowen for their expert technical assistance; and S. Richards for his care of the rats.

This work was supported by Juvenile Diabetes Foundation grants 187487 (to Dr. Kahn), 188016 (to Dr. Rossetti) and 187091 (to Dr. Shulman) and National Institutes of Health Physician Scientist Award AG-00294 (to Dr. Kahn) and grant DK-40936 (to Dr. Shulman).

\section{References}

1. DeFronzo, R. A., R. Hendler, and D. Simonson. 1982. Insulin resistance is a prominent feature of insulin-dependent diabetes. Diabetes. 31:795-801.

2. Lager, I., P. Lonnroth, H. von Schenck, and U. Smith. 1983. Reversal of insulin resistance in type I diabetes following treatment with continuous subcutaneous insulin infusion. Br. Med. J. 287:1661-1664.

3. Yki-Jarvinen, H., and V. A. Koivisto. 1984. Insulin sensitivity in newly diagnosed type I diabetics after ketoacidosis and after three months of insulin therapy. J. Clin. Endocrinol. Metab. 287:659-666.

4. Olefsky, J. M., O. G. Kolterman, and J. A. Scarlett. 1982. Insulin action and resistance in obesity and noninsulin-dependent type II diabetes mellitus. Am. J. Physiol. 243:E15-E30.

5. Scarlett, J. A., O. G. Kolterman, T. P. Ciaraldi, M. Kao, and J. M. Olefsky. 1983. Insulin treatment reverses the past receptor defect in adipocyte 3-0-methylglucose transport in type II diabetes mellitus. J. Clin. Endocrinol. Metab. 56:1195-1201.

6. Garvey, W. T., T. P. Huecksteadt, S. Matthaei, and J. M. Olefsky. 1987. Role of glucose transporters in the cellular insulin resistance of type II non-insulin-dependent diabetes mellitus. J. Clin. Invest. 81:1528-1536.

7. Rossetti, L., D. Smith, G. I. Shulman, D. Papachristou, and R. A. DeFronzo. 1987. Correction of hyperglycemia with phlorizin normalizes tissue sensitivity to insulin in diabetic rats. J. Clin. Invest. 79:1510-1515.

8. Karnieli, E., P. J. Hissin, I. A. Simpson, L. B. Salans, and S. W. Cushman. 1981. A possible mechanism of insulin resistance in the rat adipose cell in streptozotocin-induced diabetes mellitus: depletion of intracellular glucose transport systems. J. Clin. Invest. 68:811-814.

9. Kahn, B. B., and S. W. Cushman. 1987. Mechanism for markedly hyperresponsive insulin-stimulated glucose transport activity in adipose cells from insulin-treated streptozotocin diabetic rats: evidence for increased glucose transporter intrinsic activity. J. Biol. Chem. 262:5118-5124.
10. Karnieli, E., M. Armoni, P. Cohen, Y. Kanter, and R. Rafaeloff. 1987. Reversal of insulin resistance in diabetic rat adipocytes by insulin therapy: restoration of pool of glucose transporter and enhancement of glucose transporter activity. Diabetes. 36:925-931.

11. James, D. E., M. Strube, and M. Mueckler. 1989. Molecular cloning and characterization of an insulin-regulatable glucose transporter. Nature (Lond.) 338:83-87.

12. Charron, M. J., F. C. Brosius III, S. L. Alper, and H. F. Lodish. 1989. A novel glucose transporter protein expressed predominately in insulin-responsive tissues. Proc. Natl. Acad. Sci. USA. 86:2535-2539.

13. Birnbaum, M. J. 1989. Identification of a novel gene encoding an insulinresponsive glucose transporter protein. Cell. 57:305-315.

14. Fukumoto, H., T. Kayano, J. B. Buse, Y. Edwards, P. F. Pilch, G. I. Bell, and S. Seino. 1989. Cloning and characterization of the major insulin-responsive glucose transporter expressed in human skeletal muscle and other insulin-responsive tissues. J. Biol. Chem. 264:7776-7779.

15. Kaestner, K. H., R. J. Christy, J. C. McLenithan, L. T. Braiterman, P. Cornelius, P. H. Pekala, and M. D. Lane. 1989. Sequence, tissue distribution, and differential expression of mRNA for a putative insulin-responsive glucose transporter in mouse 3T3-L1 adipocytes. Proc. Natl. Acad. Sci. USA. 86:3150-3154.

16. Mueckler, M. M., C. Caruso, S. A. Baldwin, M. Panico, I. Blench, H. R. Morris, J. W. Allard, G. E. Lienhard, and H. F. Lodish. 1985. Sequence and structure of a human glucose transporter. Science (Wash. DC). 229:941-945.

17. Birnbaum, M. J., H. C. Haspel, O. M. Rosen. 1986. Cloning and characterization of cDNA encoding the rat brain glucose-transporter protein. Proc. Natl. Acad. Sci. USA. 83:5784-5788.

18. Fukumoto, H., S. Seino, H. Imura, Y. Seino, and G. I. Bell. 1988. Characterization and expression of human HepG2/erythrocyte glucose transporter gene. Diabetes. 37:657-661.

19. Zorzano, A., W. Wilkinson, N. Kotliar, G. Thoidis, B. E. Wadzinkski, A. E. Ruoho, and P. F. Pilch. 1989. Insulin-regulated glucose uptake in rat adipocytes is mediated by two transporter isoforms present in at least two vesicle populations. J. Biol. Chem. 264:12358-12363.

20. Kahn, B. B., M. J. Charron, H. F. Lodish, S. W. Cushman, and J. S. Flier. 1989. Differential regulation of two glucose transporters in adipose cells from diabetic and insulin treated diabetic rats. J. Clin. Invest. 84:404-411.

21. Garvey, T. W., T. P. Huecksteadt, and M. J. Birnbaum. 1989. Pretranslational suppression of an insulin-responsive glucose transporter in rats with diabetes mellitus. Science (Wash. DC). 245:60-63.

22. Berger, J., C. Biswas, P. Vicario, H. V. Strout, R Saperstein, and P. F. Pilch. 1989. Decreased expression of the insulin-responsive glucose transporter in diabetes and fasting. Nature (Lond.). 340:70-72.

23. Sivitz, W. I., S. L. DeSautel, T. Kayano, G. I. Bell, and J. E. Pessin 1989. Regulation of glucose transporter messenger RNA in insulin-deficient states. $\mathrm{Na}$ ture (Lond.). 340:72-74.

24. Kahn, B. B., E. S. Horton, and S. W. Cushman. 1987. Mechanism for enhanced glucose transport response to insulin in adipose cells from chronically hyperinsulinemic rats: increased translocationa of glucose transporters from an enlarged intracellular pool. J. Clin. Invest. 79:853-858.

25. Kletzien, R. F., and J. F. Perdue. 1985. Induction of sugar transport in chick embryo fibroblasts by hexose starvation. J. Biol. Chem. 250:593-600.

26. Ullrey, D., B. M. T. Gammon, and H. M. Kalckar. 1975. Uptake patterns and transport enhancements in cultures of hamster cells deprived of carbohydrates. Arch. Biochem. Biophys. 167:410-416.

27. Ullrey, D. B., and H. M. Kalckar. 1981. The nature of regulation of hexose transport in cultured mammalian fibroblasts: aerobic "repressive" control by D-glucosamine. Arch. Biochem. Biophys. 209:168-174.

28. Haspal, H. C., E. W. Vilk, M. T. Birnbaum, S. W. Cushman, and O. M. Rosen. 1986. Deprivation and hexose transporter polypeptides of murine fibroblasts. J. Biol. Chem. 261:6778-6789.

29. Rosen, O. M., C. O. Smith, C. Fung, and C. S. Rubin. 1978. Development of hormone receptors and hormone responsiveness in vitro: effect of prolonged insulin treatment on hexose uptake in 3T3-L1 adipocytes. J. Biol. Chem. 253:7579-7583.

30. Van Putten, J. P. M., and H. M. J. Krans. 1985. Glucose as a regulator of insulin-sensitive hexose uptake in 3T3 adipocytes. $J$. Biol. Chem. 260:79968001.

31. Walker, P. S., T. Ramal, J. A. Donovan, T. P. Doering, A. Sandra, A. Klip, and J. E. Pessin. 1989. Insulin and glucose-dependent regulation of the glucose transport system in the rat L6 skeletal muscle cell line. J. Biol. Chem. 264:65876595 .

32. Sasson, S., and E. Cerasi. 1986. Substrate regulation of the glucose transport system in rat skeletal muscle. J. Biol. Chem. 261:16827-16833.

33. Walker, P. S., J. A. Donovan, B. G. Van Ness, R. E. Fellows, and J. E. Pessin. 1988. Glucose dependent regulation of glucose transport activity, protein, and mRNA in primary cultures of rat brain glial cells. J. Biol. Chem. 263:1559415601 . 
34. Garvey, W. T., J. M. Olefsky, S. Matthaei, and S. Marshall. 1987. Glucose and insulin co-regulate the glucose transport system in primary cultured adipocytes. J. Biol. Chem. 262:189-197.

35. McCall, A. L., L. B. Fixman, N. Fleming, K. Tornheim, W. Chick, and N. B. Ruderman. 1986. Chronic hypoglycemia increases brain glucose transport. Am. J. Physiol. 251:E442-E447.

36. Gjedde, A., and C. Crone. 1981. Blood-brain glucose transfer: repression in chronic hyperglycemia. Science (Wash. DC). 214:456-457.

37. Sivitz, W. I., S. L. DeSautel, T. Kayano, G. I. Bell, and J. E. Pessin. 1990 Regulation of glucose transporter messenger RNA levels in rat adipose tissue by insulin. Mol. Endocrinol. 4:583-588.

38. DeFronzo, R. A., J. Tobin, and R. Andres. 1979. Glucose clamp technique: a method for quantifying insulin secretion and resistance. Am. J. Physiol. 237:E214-E223.

39. Karnieli, E., M. J. Zarnowski, P. J. Hissin, I. A. Simpson, L. B. Salans, and S. W. Cushman. 1981. Insulin-stimulated translocation of glucose transport systems in the rat adipose cell: time course, reversal, insulin concentration-dependency and relationship to glucose transport activity. J. Biol. Chem. 256:47724777

40. Foley, J. E., S. W. Cushman, and L. B. Salans. 1978. Glucose transport in isolated rat adipocytes with measurements of L-arabinose uptake. Am. J. Physiol. 234:E112-119.

41. Weber, T. M., H-G. Joost, I. A. Simpson, and S. W. Cushman. 1988. Methods for assessment of glucose transport activity and the number of glucose transporters in isolated rat adipose cells and membrane fractions. Recept. Biochem. Method. 12B:171-188.

42. Simpson, I. A., and O. Sonne. 1982. A simple, rapid and sensitive method for measuring protein concentration in subcellular membrane fractions prepared by sucrose density centrifugation. Anal. Biochem. 119:424-427.

43. Bradford, M. M. 1976. A rapid and sensitive method for quantitation of microgram quantities of protein, utilizing the principle of protein-dye binding. Anal. Biochem. 72:248-254.

44. Laemmli, U. K. 1970. Cleavage of structural proteins during the assembly of the head of bacteriophage T4. Nature (Lond.). 227:680-685.

45. James, D. E., R. Brown, J. Navarro, and P. F. Pilch. 1988. Insulin-regulatable tissues express a unique insulin-sensitive glucose transport protein. Nature (Lond.). 333:183-185.

46. Chirgwin, J. M., A. W. Przbyla, R. J. MacDonald, and W. J. Rutter. 1979. Isolation of biologically active ribonucleic acid from sources enriched in ribonuclease. Biochemistry. 18:5294-5299.

47. Maniatis, T., E. F. Frisch, and J. Sambrook. 1982. Molecular Cloning: a Laboratory Manual. Cold Spring Harbor Laboratory, Cold Spring Harbor, NY. 202-203.

48. Pedersen, O., J. F. Bak, P. H. Andersen, S. Lund, D. E. Moller, J. S. Flier and B. B. Kahn. 1990. Evidence against altered expression of Glut 1 or Glut4 in skeletal muscle of patients with obesity or NIDDM. 1990. Diabetes. 39:865-870.
49. Spiegelman, B. M., and S. R. Farmer. 1982. Decreased in tubulin and actin gene expression prior to morphological differentiation of 3T3 adipocytes. Cell. 29:53-60.

50. Albano, J. D. M., R. P. Ekino, I. Maritz, and R. C. Turner. 1972. A sensitive, precise radioimmunoassay of serum insulin relying on charcoal separation of bound and free hormone moieties. Acta. Endocrinol. 70:487-509.

51. Horuk, R., S. Matthaie, J. M. Olefsky, D. L. Baly, S. W. Cushman, and I. A. Simpson. 1986. Biochemical and functional heterogeneity of rat adipocyte glucose transporters. J. Biol. Chem. 261:1823-1828.

52. Haspel, H. C., M. Rosenfeld, and O. M. Rosen. 1988. Characterization of antisera to a synthetic carboxyl-terminal peptide of the glucose transporter protein. J. Biol. Chem. 263:398-403.

53. Oka, Y., T. Asano, Y. Shibaski, M. Kasuga, Y. Kanazawa, and F. Takaku. 1988. Studies with antipeptide antibody suggest the presence of at least two types of glucose transporter in rat brain and adipocyte. J. Biol. Chem. 263:1343213439.

54. Guerre-Millo, M., M. Lavau, J. S. Horne, and L. J. Wardzala. 1985. Proposed mechanism for increased insulin-mediated glucose transport in adipose cells from young, obese Zucker rats: large intracellular pool of glucose transporters. J. Biol. Chem. 260:2197-2201.

55. Tordjman, K. M., K. A. Leingang, D. E. James, and M. M. Mueckler. 1989. Differential regulation of two distinct glucose transporter species expressed in 3T3-Ll adipocytes: effect of chronic insulin and tolbutamide treatment Proc. Natl. Acad. Sci. USA. 86:7761-7765.

56. Kosaki, A., H. Kuzuya, Y. Yoshimasa, K. Yamada, M. Okamoto, H. Nishimura, T. Kakehi, J. Takeda, Y. Seino, and H. Imura. 1988. Regulation of glucose transporter gene expression by insulin in cultured human fibroblasts. Diabetes. 37:1583-1585.

57. Rossetti, L., and M. R. Laughlin. 1989. Correction of chronic hyperglycemia with vanadate, but not phlorizin, normalizes in vivo glycogen repletion and in vitro glycogen synthase activity in diabetic skeletal muscle. J. Clin. Invest. 84:892-899.

58. Rossetti, L., and A. Giaccari. 1990. Relative contribution of glycogen synthesis and glycolysis to insulin-mediated glucose uptake. J. Clin. Invest. 85:1785-1792.

59. Traxinger, R. R., and S. Marshall. 1989. Recovery of maximal insulin responsiveness and insulin sensitivity after induction of insulin resistance in primary cultured adipocytes. J. Biol. Chem. 264:8156-8163.

60. Bogardus, C., S. Lillioja, D. Mott, G. M. Reaven, A. Kashiwagi, and J. E. Foley. 1984. Relationship between obesity and maximal insulin-stimulated glucose uptake in vivo and in vitro in Pima Indians. J. Clin. Invest. 73:800-805.

61. DeFronzo, R. A., E. Jacot, E. Jequier, E. Maeder, J. Wahren, and J. P. Felber. 1981. The effect of insulin on the disposal of intravenous glucose. Dia betes. 30:1000-1007.

62. Richter, E. A., B. F. Hansen, and S. A. Hansen. 1988. Glucose-induced insulin resistance of skeletal-muscle glucose transport and uptake. Biochem. $J$. 252:733-737. 